\section{Antimicrobianos, resistencia antibacteriana y salud sostenible}

\author{
María J. Pons ${ }^{1 \oplus}$, María de Toro $^{2 \oplus}$, Susan Medina ${ }^{3 \oplus}$, \\ Yolanda Sáenz ${ }^{4}{ }^{\oplus}$, Joaquim Ruiz ${ }^{1 *}$
}

Antimicrobial agents,

antibacterial resistance and sustainable health
1 Laboratorio de Microbiología Molecular y Genómica Bacteriana, Universidad Científica del Sur, Lima, Perú.

2 Plataforma de Genómica y Bioinformática, Centro de Investigación Biomédica de La Rioja (CIBIR), Logroño, España.

3 Universidad Científica del Sur, Lima, Perú.

4 Área de Microbiología Molecular, Centro de Investigación Biomédica de La Rioja (CIBIR), Logroño, España.

\section{SOUTH} SUSTAINABILITY

Citar como: Pons, M.J., de Toro, M., Medina, S., Sáenz, Y. y Ruiz, J. (2020). "Antimicrobianos, resistencia antibacteriana y salud sostenible».

South Sustainability, 1(1), e001 DOI: 10.21142/SS-0101-2020-001

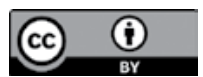

(C) Los autores 2020. Publicado por la Universidad Científica del Sur (Lima, Perú)

${ }^{*} E$-mail de correspondencia: joruiz.trabajo@gmail.com
Desde los albores de los sistemas sanitarios, su función ha sido la promoción y protección de la salud, así como la prevención de enfermedades, buscando maximizar la duración y la calidad de vida de la población a la que asisten. Para ser alcanzable, ello solo se puede hacer desde una perspectiva sostenible, que permita garantizar que los avances logrados no reviertan a medio o largo plazo. Así, los objetivos para alcanzar una salud sostenible se han dirigido a consolidar estrategias tanto para alargar el tiempo como la calidad de vida. Así, se han diseñado medidas a diferentes niveles, sanitarios y sociales. Entre estas últimas, destacan las direccionadas a erradicar la pobreza y garantizar el acceso a agua potable y saneamiento para un control de las enfermedades infecciosas.

Además de estas medidas, se han producido dos eventos clave: la creación de las vacunas y el descubrimiento de los antibióticos. Las primeras han sido la herramienta clave para el control, la prevención e incluso la erradicación de algunas enfermedades. Los segundos son el eje fundamental del tratamiento de las enfermedades de origen bacteriano. No podríamos entender el mundo sin antibióticos, hasta el punto de que en apenas 80 años se han convertido en algo cotidiano e imprescindible. Los antibióticos no son una invención humana, son productos de origen natural (o en su práctica totalidad derivan de él) y están presentes en la naturaleza desde hace millones de años, el mismo tiempo que las bacterias han estado en contacto con ellos y, por simple azar, algunas de ellas han desarrollado mecanismos para sobrevivir en su presencia. Pese a la evidencia, y a haber reportes de cepas resistentes a penicilina aun antes de la introducción de este antibiótico en la práctica clínica (Abraham y Chain, 1940), esta realidad permaneció ignorada durante años debido a los excelentes resultados derivados de la aplicación de antibióticos en el tratamiento de las enfermedades infecciosas. En esos años el uso de antibióticos se intensificó a niveles realmente inconcebibles y se expandió más allá de la sanidad humana. Todo ello conllevó la descripción esporádica de bacterias resistentes que, de rareza digna de ser publicada, pasaron a frecuentes, de frecuentes a cotidianas, de cotidianas a situación de emergencia y de ahí a la descripción de cepas panresistentes; es decir, capaces de resistir a la presencia de todo antimicrobiano conocido.

En la actualidad la resistencia a antibióticos es la causa de 700000 muertes anuales a nivel mundial, con tendencia a incrementarse, y se estima, en los escenariosmásnegativos, que podrían ser 10000000 en 2050 (O'Neill, 2014; World Health Assembly, 2015). Además de incrementos de mortalidad, la resistencia a antimicrobianos también causa pérdidas económicas que se relacionan con estancias hospitalarias más prolongadas, tratamientos más costosos, mayor morbilidad y horas dejadas de trabajar por pacientes o acompañantes, a lo que 
habría que añadir costes sociales vinculados, entre otras causas, a desplazamiento o estancia de los acompañantes. Adicionalmente, también comporta pérdidas económicas e incrementos de costes en sectores productivos como la ganadería o la acuicultura.

Un estudio del Banco Mundial ha estimado que en 2050, en un escenario de elevados niveles de resistencia a antimicrobianos, el sobrecoste sanitario rozaría los US\$ 1,2 billones, mientras que a nivel de producto interno bruto (PIB) se traduciría en descensos del PIB del 3,2 \% y $3,8 \%$ en 2030 y 2050 , respectivamente, lo que afecta de manera desigual a los países según su renta. Así, en 2050 serían esperables pérdidas del PIB del 5,6 \% en países de baja renta y del $4,4 \%$ en países de media renta, como es el caso del Perú, mientras que en los países de alta renta las pérdidas se limitarían al 3,1 \% (World Bank Group, 2017). Para magnificar lo que significa esa reducción basta indicar que, usando datos del PIB de 2018 en el Perú, supondría una pérdida del orden de S/ 31284 millones, equivalente a reducir a casi la mitad el aporte de la minería peruana a la riqueza nacional.

Estos datos de morbimortalidad y de efectos sobre la economía se refieren al conjunto de microorganismos patógenos, pero no todos ellos tienen el mismo impacto. Así, los llamados microorganismos del grupo ESKAPE (Enterococcus faecium, Staphylococcus aureus, Klebsiella pneumoniae, Acinetobacter baumannii, Pseudomonas aeruginosa y Enterobacter spp.), junto con Escherichia coli, están entre los de mayor relevancia, tanto por sus ya elevados niveles de resistencia como por su persistencia (Pons y Ruiz, 2019). Estos microorganismos han supuesto la necesidad de usar antibióticos con relevantes efectos secundarios como la colistina e, inclusive, como se ha indicado, ya se han detectado cepas panresistentes (Chen et al., 2017). Asimismo, son notables sus efectos sobre la supervivencia de los pacientes infectados y su adaptación a medios hospitalarios, donde son la principal causa de infecciones hospitalarias y tienen un impacto demoledor en las unidades de cuidados intensivos (UCI) (Pons y Ruiz, 2019). Así, algunos estudios muestran tasas de mortalidad en UCl de alrededor del $40 \%$ en pacientes colonizados por Enterobacteriaceae resistentes a antibióticos carbapenémicos, que descienden a $28 \%$ en enterobacterias sensibles a estos antimicrobianos (Oliveira de Matos et al., 2018). Similarmente, el retraso en el tratamiento antibiótico adecuado se ha asociado a incrementos de mortalidad en pacientes con bacteriemia por $P$. aeruginosa, y este retraso se vincula de manera directa a la presencia de multirresistencia (Lodise et al., 2007). En este sentido, se debe considerar que las poblaciones bacterianas no son uniformes (hay numerosas variantes genéticas dentro de cada especie concreta) y la presencia-ausencia de diferentes genes puede favorecer tanto una mayor virulencia como el desarrollo de elevados niveles de resistencia (Horna et al., 2019).
Como se ha indicado anteriormente, la resistencia a antibióticos no es un fenómeno nuevo. Existen estudios desarrollados sobre muestras de más de 30000 años en las que se ha detectado la presencia de genes de resistencia (D'Costa et al., 2011). Sin embargo, en la era «preantibiótica» las concentraciones de antibiótico en la naturaleza eran anecdóticas, por lo que la presencia de mecanismos bacterianos de resistencia era escasa, en especial debido a que suelen comportar un coste biológico para la bacteria. La presencia de antibiótico de manera muy local podía alcanzar concentraciones significativas, aunque solo en circunstancias muy concretas, con una clara circunscripción geográfica, y aun así relacionadas con la actividad humana (Bassett et al., 1980). De hecho, la actual situación deriva en gran medida de los elevados niveles de uso de antimicrobianos que han eliminado selectivamente las poblaciones bacterianas sensibles a antibióticos, lo que ha generado un vacío ecológico, ocupado por microorganismos resistentes. Pero no estamos hablando solo de patógenos humanos, sino también de bacterias comensales presentes en nuestras microbiotas y muy especialmente de microorganismos de origen animal o ambiental. Estos microorganismos no patógenos son genuinos caballos de Troya, pues no solo adquieren resistencia a antibióticos merced al desarrollo de mutaciones cromosomales, sino que almacenan genes de resistencia de naturaleza transferible (plásmidos, transposones), en ambientes muy diversos, con lo cual actúan como reservorios y, por ende, como perpetuadores invisibles de la resistencia a antimicrobianos.

$\mathrm{Si}$ pensamos que los niveles de resistencia a antimicrobianos se relacionan con su uso, podemos caer en el error de ver el problema como un asunto estrictamente local y reversible, y no es así. El mundo actual no es un conjunto de compartimentos estancos, ajenos entre sí. Existe una interrelación directa entre zonas geográficas lejanas, un trasiego constante de personas, alimentos, animales, mercancías, que hace devenir esas regiones distantes meros anexos contiguos, simples vasos comunicantes. Ese trasegar lo hacen llevando sus propias bacterias y sus propios mecanismos de resistencia, que así se desplazarán cientos o miles de kilómetros, y pueden tanto establecerse manteniendo sus genes de resistencia como transferir esos genes a microorganismos locales. Pero no solo nuestras actividades directas implican desplazamiento de bacterias: hay mecanismos de dispersión, como las aguas, ya sean residuales, fluviales o marinas, o animales migratorios, que cumplen con eficiencia esta misión (Ruiz, 2018; Mathys et al., 2017). Más aún, aparte de la propia diseminación de bacterias y genes, restos de antimicrobianos se concentran en ríos y llegan a aguas marinas, se esparcen en vertederos o se acumulan en suelos, hasta llegar a animales salvajes y ejercer así una presión continua en esos ambientes. Los antibióticos son uno de los ejemplos paradigmáticos del «efecto mariposa», porque aunque ejerzan una presión selectiva 
en un ambiente concreto, la generación o selección de resistencias puede afectar zonas remotas y poblaciones ajenas a su uso (Pallecchi et al., 2012).

Todo lo citado, salvo el caso de viajeros o animales enfermos, o aun de alimentos importados en los que se teste la presencia de patógenos humanos, es una diseminación geográfica o selección de resistencia que pasa inadvertida, que no vemos, pero es real. Podemos pensar que no nos afecta que bacterias no patógenas de la microbiota intestinal de un pececillo cualquiera, sin interés pesquero ni comercial, presenten resistencia a ciertos antibióticos, pero esas bacterias resistentes podrían llegar a nosotros de una manera directa a través de la cadena alimentaria -como la transferencia de esos genes a peces de interés comercial, lo que produce que esos genes de resistencia se hagan accesibles para nuestras bacterias comensales, que luego podrían transferirlos a bacterias patógenas - o indirecta - al transitar por diferentes huéspedes o ambientes hasta alcanzarnos-. Por tanto, debemos ver el problema de la resistencia a los antibióticos como un problema poliangular.

Para controlar la situación y minimizar los impactos de la resistencia a antimicrobianos es preciso desarrollar políticas y acciones, tanto en el ámbito del manejo clínicohospitalario, comoen el mundoanimalyel medioambiente. Se deben incorporar componentes como el conocimiento de las estructuras y dinámicas poblacionales bacterianas y, muy especialmente, se debe hacer hincapié en áreas sociales. Solo políticas que pivoten y consideren esos tres ángulos (humanos, animales y ambiente) podrán ofrecer soluciones efectivas y sostenibles.

Pero para que esas políticas sean efectivas hace falta convertir las palabras en realidades. Se ha avanzado. Se ha catalogado la lucha contra la resistencia a antibióticos como una de las prioridades de los objetivos de desarrollo sostenible (PNUD, s. f.). Más aún, algunos antibióticos fueron listados como medicamentos esenciales por la Organización Mundial de la Salud (OMS), considerando que su actividad debía ser preservada para el bien de las generaciones futuras (Sharland et al., 2018). En la misma línea, en 2015 la OMS alumbró un plan mundial para combatir la resistencia a antimicrobianos. También, el 21 de septiembre de 2016, la problemática de la resistencia a antimicrobianos fue motivo de una sesión plenaria de la ONU; tras el VIH y el ébola, la resistencia a antimicrobianos tuvo el dudoso honor de ser la tercera problemática relacionada con las enfermedades infecciosas que fue tratada en el más alto foro político a nivel mundial. Pese a ello, el libre acceso a los antimicrobianos sigue siendo una realidad en numerosos países.

El uso de antimicrobianos en la cría de animales destinados al consumo humano, incluyendo la acuicultura, sigue siendo abusivo, descontrolado e innecesario en su mayoría, sin considerar las consecuencias presentes y futuras. Más aún, el uso de antibióticos presentes en la lista de medicamentos esenciales es habitual en el ámbito de la ganadería y la acuicultura, aun en ausencia de patologías infecciosas. La educación sanitaria de la población general sigue siendo deficiente en prácticamente el mundo entero; cientos de millones de personas siguen pensando en los antibióticos como en la panacea universal que puede curar cualquier enfermedad, y siguen comprándolos sin control en farmacias, físicas $u$ online, o pidiendo y presionando a sus médicos para obtenerlos por las vías legalmente establecidas. Y también, hay que decirlo, el uso de antibióticos por parte de los profesionales del mundo de la medicina es manifiestamente mejorable en numerosos lugares. Y sí, no hay que olvidar las limitaciones de los sistemas de salud, sean diagnósticas, de escasez de personal cualificado e incluso higiénicas, o de irregularidad y de carencias de suministros médicos, que siguen vigentes en numerosas zonas de baja renta, que no hacen más que alimentar el problema. Estos problemas contribuyen a la generación, selección o establecimiento de poblaciones bacterianas resistentes a antimicrobianos. Sin políticas integradoras que exploren las interfases entre los diferentes ambientes (animalambiente-humano) para atajar la diseminación global de microorganismos resistentes a antimicrobianos o de restos de antimicrobianos, sin aproximaciones globales que sean sostenibles y sostenidas, sin una visión poliédrica del problema lejana de la clásica visión antropocéntrica, cualquier medida que se proponga tendría un alcance limitado.

Hace muchos años que se habla del cambio climático, y la realidad es que las acciones que se han de emprender para mitigar el problema siguen en su mayoría en la casilla de partida. Con la resistencia a antibióticos pasa lo mismo, solo que aún no existe una percepción clara de sus consecuencias por la mayor parte de la población. Y lo que es peor, lo que percibimos es como ver a un hipopótamo en un río: solo vemos las orejas, y el hipopótamo es uno de los animales salvajes más peligrosos que existen.

\section{Agradecimientos}

Este trabajo fue financiado por el Fondo Nacional de Desarrollo Científico, Tecnológico y de Innovación Tecnológica (Fondecyt, Perú) en el marco del «Proyecto de Mejoramiento y Ampliación de los Servicios del Sistema Nacional de Ciencia, Tecnología e Innovación Tecnológica» (número de contrato 08-2019-FONDECYT-BM-INC-INV). 


\section{Referencias Bibliográficas}

Abraham, E. P. y Chain, E. (1940). «An enzyme from bacteria able to destroy penicillin». Nature, 146, pp. 837.

Bassett, E. J., Keith, M. S., Armelagos, G. J., Martin, D. L. y Villanueva, A. R. (1980). "Tetracycline-labeled human bone from ancient Sudanese Nubia (A.D. 350)». Science, 209, pp. 1532-1534. DOI: 10.1126/science.7001623.

Chen, L., Todd, R., Kiehlbauch, J., Walters, M. y Kallen, A. (2017). «Pan-resistant New Delhi Metallo- $\beta$-lactamase-producing Klebsiella pneumoniae. Washoe County, Nevada». Morbidity and Mortality Weekly Report, 66, pp. 33. DOI: 10.15585/mmwr.mm6601a7.

D'Costa, V. M., King, C. E., Kalan, L., Morar, M., Sung, W. W., Schwarz, C., Froese, D., Zazula, G., Calmels, F., Debruyne, R., Golding, G. B., Poinar, H. N. y Wright G. D. (2011). "Antibiotic resistance is ancient». Nature, 477, pp. 457-461. DOI: 10.1038/ nature10388.

Horna, G., Amaro, C., Palacios, A., Guerra, H. y Ruiz J. (2019). «High frequency of the exoU+/exoS+ genotype associated with multidrugresistant «high-risk clones» of Pseudomonas aeruginosa clinical isolates from Peruvian hospitals». Scientific Reports, 9, pp. 10874. DOI: 10.1038/s41598-019-47303-4.

Lodise, T. P. Jr., Patel, N., Kwa, A., Graves, J., Furuno, J. P., Graffunder, E., Lomaestro B. y McGregor J. C. (2007). "Predictors of 30day mortality among patients with Pseudomonas aeruginosa bloodstream infections: impact of delayed appropriate antibiotic selection". Antimicrobial Agents and Chemotherapy, 51, pp. 35103515. DOI: 10.1128/AAC.00338-07.

Mathys, D. A., Mathys, B. A., Mollenkopf, D. F., Daniels, J. B. y Wittum, T. E. (2017). «Enterobacteriaceae harboring AmpC (bla $\left.a_{\mathrm{CMY}}\right)$ and ESBL $\left(b / a_{\mathrm{CTX}-\mathrm{M}}\right)$ in migratory and nonmigratory wild songbird populations on Ohio dairies». Vector Borne Zoonotic Diseases, 17, pp. 254-259. DOI: 10.1089/vbz.2016.2038.

Oliveira de Matos, E. C., Andriolo, R. B., Rodrigues, Y. C., Lima de Lima, P. D., Souza Carneiro, I. C. R. y Batista Lima K. V. (2018). "Mortality in patients with multidrug-resistant Pseudomonas aeruginosa infections: a meta-analysis». Revista da Sociedade Brasileira de Medicina Tropical, 51, pp. 415-420. DOI: 10.1590/00378682-0506-2017.
O’Neill J. (2014). "Antimicrobial resistance: Tackling a crisis for the health and wealth of nations". Disponible en: https://amrreview. org/sites/default/files/AMR\%20Review\%20Paper\%20-\%20 Tackling\%20a\%20crisis\%20for\%20the\%20health\%20and\%20 wealth\%20of\%20nations_1.pdf

Pallecchi, L., Bartoloni, A., Riccobono, E., Fernández, C., Mantella, A., Magnelli, D., Mannini, D., Strohmeyer, M., Bartalesi, F., Rodriguez, H., Gotuzzo, E. y Rossolini G. M. (2012). «Quinolone resistance in absence of selective pressure: the experience of a very remote community in the Amazon forest». PLoS Neglected Tropical Diseases, 6, pp. e1790. DOI: 10.1371/journal.pntd.0001790.

Pons, M. J. y Ruiz, J. (2019). "Current trends in epidemiology and antimicrobial resistance in intensive care units». Journal of Emergency and Critical Care Medicine, 3, pp. 5. DOI: 10.21037/jeccm.2019.01.05.

Programa de las Naciones Unidas para el Desarrollo. (S. f.). "Objetivos de Desarrollo Sostenible. Salud y bienestar». Disponible en: https:// www.undp.org/content/undp/es/home/sustainable-developmentgoals/goal-3-good-health-and-well-being.html

Ruiz, J. (2018). "Reflexión acerca del concepto de "Una Salud" ». Revista Peruana de Medicina Experimental y Salud Publica, 35, pp. 657-662. DOI: 10.17843/rpmesp.2018.354.3821.

Sharland, M., Pulcini, C., Harbarth, S., Zeng, M., Gandra, S., Mathur, S., Magrini, N. (2018). "Classifying antibiotics in the WHO Essential Medicines List for optimal use-be AWaRe». Lancet Infectious Diseases, 18, pp. 18-20. DOI: 10.1016/S1473-3099(17)30724-7

World Bank Group. (2017). Drug-resistant infections. A threat to our economic future. Washington D. C.: International Bank for Reconstruction and Development y The World Bank.

World Health Assembly. (2015). "Global action plan on antimicrobial resistance». Disponible en: http://apps.who.int/gb/ebwha/pdf files/WHA68/A68_R7-en.pdf?ua=1 